\title{
FATORES RELEVANTES NAS ATIVIDADES EXPERIMENTAIS NO ENSINO DE CIÊNCIAS
}

\author{
RELEVANT FACTORS IN EXPERIMENTAL ACTIVITIES IN SCIENCE TEACHING
}

FACTORES RELEVANTES EN ACTIVIDADES EXPERIMENTALES EN LA ENSEÑANZA DE LAS CIENCIAS

\author{
QUELEN COLMAN ESPÍNDOLA LIMA \\ MARA REGINA BONINI MARZARI² \\ SIMONE PINTON ${ }^{3}$
}

\section{RESUMO}

0 presente estudo teve como objetivo investigar o contexto da experimentação no ensino de Ciências, no que tange a definição conceitual, as percepções e os objetivos acerca das atividades experimentais, assim como a frequência, os procedimentos e as necessidades para a efetivação de tais práticas. Trata-se de uma pesquisa de campo de natureza qualitativa, que teve como sujeitos, 63 professores atuantes no ensino de Ciências do Ensino Fundamental II das escolas públicas urbanas do município de Uruguaiana/RS. Para a coleta dos dados utilizou-se um questionário e a análise dos mesmos deu-se por meio da Análise de Conteúdo. Os resultados descritos denotam que a experimentação é considerada relevante à aprendizagem dos estudantes, mas há inúmeras incompreensões quanto a finalidade dessa prática nas aulas de Ciências. Considera-se que este estudo apresenta importantes constatações que poderão contribuir tanto para o contexto pesquisado, quanto para a área do ensino de Ciências.

Palavras-chave: Ensino Fundamental. Experimentação. Professores de Ciências.

\section{ABSTRACT}

The present study aimed to investigate the context of experimentation in Science teaching, regarding the conceptual definition, the perceptions and the objectives about the experimental activities, as well as frequency, procedures and needs for the implementation of such practices. It is a qualitative field research, which had as subject 63 teachers working in the teaching of Elementary School Sciences in urban public schools in the municipality of Uruguaiana/RS. For data collection was used a questionnaire, and its analysis took place through Content Analysis. The results described show that experimentation is considered relevant to student learning; however, there are numerous misunderstandings regarding the purpose of this practice in Science classes. We consider that this study presents important findings that may contribute both to the researched context and to the area of Science teaching.

Keywords: Elementary School. Experimentation. Science teachers.

\section{RESUMEN}

El presente estudio tuvo como objetivo investigar el contexto de la experimentación en la enseñanza de la ciencia, con respecto a la definición conceptual, las percepciones y los objetivos sobre las actividades experimentales, así como la frecuencia, los procedimientos y las necesidades para la implementación de tales prácticas. Es una investigación de

\footnotetext{
1 Doutoranda em Bioquímica Toxicológica. Universidade Federal de Santa Maria. E-mail: quelenespindola13@gmail.com. Orcid: https://orcid. org/0000-0001-8343-2279.

2 Doutora em Ciências. Professora Adjunta da Universidade Federal do Pampa, Uruguaiana - RS. E-mail: maramarzari@unipampa.edu.br. Orcid: https://orcid.org/0000-0001-8235-1514.

3 Doutora em Ciências Biológicas. Professora Adjunta da Universidade Federal do Pampa, Uruguaiana - RS. E-mail: simonepinton@unipampa.edu.br. Orcid: https://orcid.org/0000-0001-7870-9579.
} 
campo cualitativa, que tenían como sujetos, 63 maestros que trabajan en la enseñanza de Ciencias de la Educación Primaria II en escuelas públicas urbanas del municipio de Uruguaiana/RS. Para la recopilación de datos, se utilizó un cuestionario y su análisis se realizó a través del Análisis de Contenido. Los resultados descritos muestran que la experimentación se considera relevante para el aprendizaje de los estudiantes, pero existen numerosos malentendidos con respecto al propósito de esta práctica en las clases de Ciencias. Se considera que este estudio presenta hallazgos importantes que pueden contribuir tanto al contexto investigado como al área de educación científica.

Palabras-clave: Educación primaria. Experimentación. Profesores de Ciencias.

\section{INTRODUÇÃO}

A experimentação no ensino de Ciências é uma temática amplamente estudada e sustentada por inúmeros pesquisadores como Krasilchik (1987), Giordan (1999), Galiazzi e Gonçalves (2004), Rosito (2008), Marcondes et al. (2009), Zancul (2011), entre outros. Trata-se de uma alternativa metodológica que favorece a aproximação e a interação entre 0 aluno e 0 conhecimento científico, dinamizando o processo de ensino-aprendizagem em Ciências.

Diante de sua relevância a essa área, a prática da experimentação é prevista nos principais documentos normativos da Educação Básica, a saber: as Diretrizes Curriculares Nacionais (DCN) (BRASIL, 2013) e a Base Nacional Comum Curricular (BNCC) (BRASIL, 2017) a nível nacional; 0 Referencial Curricular Gaúcho (RCG) (RIO GRADE DO SUL, 2018) a nível estadual, referindo-se ao estado do Rio Grande do Sul onde desenvolveu-se este estudo. De modo geral, em tais documentos a experimentação é compreendida como uma estratégia de ensino que confere qualidade ao ensino de Ciências, uma vez que permite correlações entre o conhecimento científico e sua aplicabilidade ao meio em que vivemos.

Entretanto, devido a diversos fatores, como as lacunas formativas dos professores de Ciências e a indisponibilidade de estrutura física e de materiais, as atividades experimentais ainda são pouco frequentes nas escolas brasileiras (KRASILCHIK, 2008; LANGHI, 2017). Adicionalmente a estes, outros tantos fatores podem estar dificultando ou inviabilizando o desenvolvimento da experimentação no ensino de Ciências. Conforme Oliveira (2010), o desconhecimento referente às finalidades, às abordagens e aos objetivos de tais atividades junto aos alunos e as distorções e equívocos acerca da conceituação das mesmas (BASSOLI, 2014) também podem comprometer o processo de efetivação dessas práticas.

Cabe ressaltar, que assim como as aulas meramente expositivas predominam no sistema educacional vigente (CERRI; TOMAZELLO, 2011), a maioria das atividades experimentais, quando desenvolvidas, ainda preservam contornos estritamente tradicionais. Trata-se de uma perspectiva que perdura desde a década de 50, em que o foco principal consiste na execução sistêmica dos procedimentos, na direção de um resultado já previsto (GIANI, 2010; MOREIRA; PINHÃO, 2018). Portanto, é fundamental que os professores tenham conhecimento tanto sobre aplicabilidade da experimentação, quanto de suas potencialidades e possíveis limitações no ensino de Ciências (OLIVEIRA, 2010).

Diante do exposto, é relevante elucidar junto aos professores atuantes no ensino deste componente curricular, as particularidades que envolvem a prática das atividades experimentais no âmbito educacional. Nesse sentido, o presente estudo, o qual é parte integrante de uma pesquisa de Mestrado, buscou compreensões acerca das percepções dos professores de Ciências das escolas de Uruguaiana/RS sobre a referida temática. Sendo que o problema de pesquisa centrou-se na seguinte 
questão: Que fatores permeiam o contexto das atividades experimentais no ensino de Ciências nos anos finais do nível Fundamental das escolas de Uruguaiana/RS?

Assim, com base nos direcionamentos desta questão, objetivou-se diagnosticar como os professores conceituam a experimentação no ensino de Ciências; qual a percepção sobre a realização de experimentos; e quais objetivos atribuem a essa prática junto aos alunos. Ainda, buscou-se constatar se os professores realizam ou não atividades experimentais, e em caso afirmativo, com que frequência e em que momento do processo de ensino-aprendizagem; quais os principais procedimentos utilizados; bem como as demandas emergentes que facilitariam a inserção das atividades experimentais no ensino de Ciências.

\section{DIRECIONAMENTO TEÓRICO}

A experimentação com viés didático tem sido abordada sob diversas perspectivas. Os estudos transitam desde a priorização do método científico, até proposições voltadas ao desenvolvimento integral do aluno. No presente estudo, os aportes teóricos estão alicerçados em pressupostos consoantes à última perspectiva descrita, tendo o estudante como foco, pois presume-se que as atividades experimentais, se bem exploradas, possuem potencialidades que transcendem os aspectos exclusivamente procedimentais.

Visando melhor explicitar esse contexto, utilizamos como principal fundamentação teórica, os direcionamentos propostos por Zanon e Freitas (2007), apresentados por meio de um esquema elaborado com base na ferramenta analítica desenvolvida por Mortimer e Scott (2003) (Figura 1). 0 referido esquema retrata as principais etapas a serem consideradas no desenvolvimento das atividades experimentais no ensino de Ciências, associadas às análises: dos Focos de ensino, referentes às intenções do professor e ao conteúdo; da Abordagem, relativa à comunicação estabelecida entre os sujeitos; e das Ações, que compreendem os padrões de interação e as intervenções do professor (MORTIMER; SCOTT, 2003).

De acordo com a esquematização das autoras, a análise dos focos de ensino, da abordagem e das ações, está intrinsecamente correlacionada às etapas de elaboração do problema, formulação de hipóteses e realização da atividade experimental. Ainda, há o direcionamento de que as referidas etapas e a posterior conclusão da atividade configurem-se como etapas não lineares, visto que cada uma delas pode ser retomada pelos estudantes a qualquer momento da prática, (ZANON; FREITAS, 2007). A partir disso, a atividade experimental assume maiores potencialidades junto ao processo de ensino-aprendizagem em Ciências e pode contribuir significativamente ao desenvolvimento dos estudantes.

Referindo-se ao foco de ensino em meio à prática da experimentação, que contempla a intenção do professor e o conteúdo a ser trabalhado junto aos estudantes (MORTIMER; SCOTT, 2003), é imperativo que o professor tenha bem definido o objetivo que pretende atingir com a execução da atividade (BORGES, 2002). Para tanto, é fundamental que esse professor conheça tanto as potencialidades, quanto as particularidades da experimentação para o ensino de Ciências. Algumas incompreensões sobre esse contexto podem comprometer o êxito das atividades, reduzindo ou anulando as possíveis contribuições à aprendizagem dos estudantes (OLIVEIRA, 2010). Por exemplo, "as atividades experimentais, quando se destinam a ilustrar ou a comprovar teorias, são limitadas e não favorecem a construção de conhecimento pelo aluno" (ZANON; FREITAS, 2007, p. 94). 
Figura 1 - Integração das atividades investigativas e a estrutura de análise

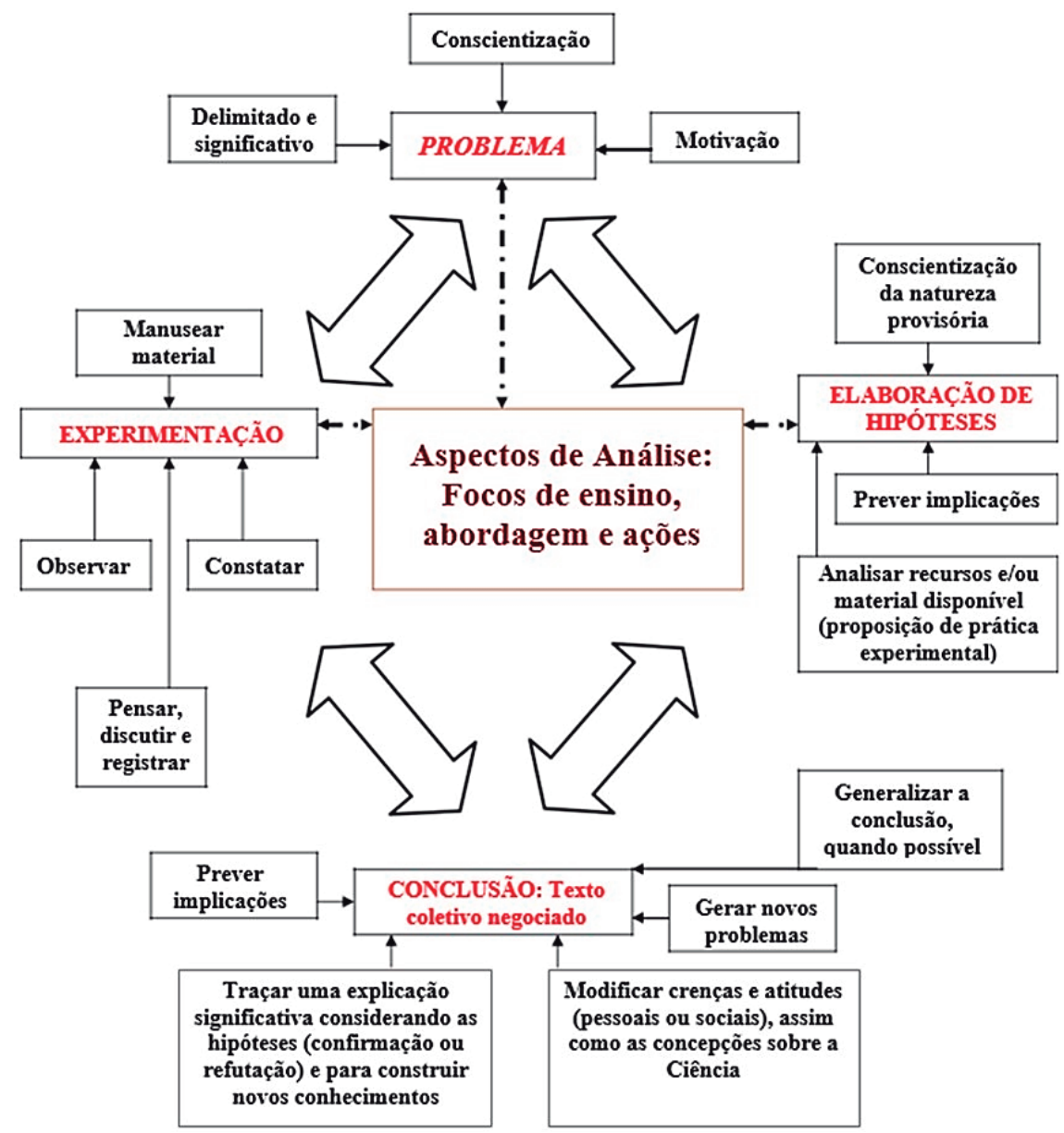

Fonte: Zanon e Freitas (2007, p. 102).

É oportuno destacar também, que para o desenvolvimento das habilidades cognitivas dos estudantes, a abordagem comunicativa entre o professor e 0 aluno deve ser flexibilizada com 0 "poder" de fala para todos e orientada para que não haja grandes desvios do objetivo pretendido (ZANON; FREITAS, 2007). Destaca-se que o estabelecimento dessa comunicação deve perpassar todas as etapas da atividade, cabendo ao professor instigar os estudantes a dialogar, refletir, opinar e debater sobre cada momento do processo (SILVA; MARCONDES, 2017). Assim, a partir de questionamentos previa e intencionalmente elaborados, o professor tem a possibilidade de explorar mais efetivamente o tema proposto para estudo, bem como as capacidades dos estudantes. Isso não impede o surgimento de novos questionamentos ao decorrer atividade, seja por parte do professor ou dos estudantes. Pelo contrário, entende-se que ao questionar o professor, o estudante está demonstrando interesse em sanar dúvidas necessárias à construção do seu conhecimento acerca de determinado objeto ou fenômeno de estudo, bem como denota uma postura ativa frente à situação apresentada.

Acerca das ações, referindo-se às interações e às intervenções do professor (MORTIMER; SCOTT, 2003), importa que o professor atue como orientador, mediador e assessor da atividade 
experimental (ZANON, FREITAS, 2007). Para isso, é sumariamente importante o professor observar com atenção 0 desenvolvimento de cada etapa da atividade, de modo a verificar a evolução dos estudantes e as possíveis incompreensões conceituais e dificuldades procedimentais e atitudinais frente à prática. É relevante atentar também ao fato de que além da fala, os gestos também auxiliam na expressão de ideias (SASSERON, 2013), outro aspecto que pode favorecer o professor na identificação de determinados entraves em meio ao prosseguimento da atividade.

0 acompanhamento descrito facilitará a interação e a intervenção do professor com os direcionamentos necessários aos estudantes, o que favorecerá tanto a execução da atividade, quanto as aprendizagens propiciadas por ela. Zanon e Freitas (2007, p. 94) ainda destacam que as orientações do professor "devem oferecer condições para que os alunos possam levantar e testar suas ideias e/ou suposições sobre os fenômenos científicos a que são expostos" sem portanto, prejudicar ou reduzir o protagonismo e a autonomia dos mesmos.

Ao observarmos a proposição de Zanon e Freitas (2007), é importante destacar alguns pontos. Por exemplo, há o direcionamento para que o problema norteador da atividade experimental, seja significativo aos estudantes. Ou seja, alguma situação previamente conhecida que motive esses sujeitos a tentar resolvê-la por meio da experimentação (CARVALHO, 2013). Na etapa referente à elaboração de hipóteses, é destacado ser necessário prever as possíveis implicações do fenômeno. Pode-se abordar por exemplo, a transposição da situação a ser observada na atividade experimental, para determinados contextos vivenciados no dia a dia, atentando às interações e inferências que podem ocorrer ao meio ambiente e/ou à sociedade de modo geral.

Quanto ao momento procedimental da prática, além da questão do manuseio dos materiais, da observação e dos registros sobre essas observações, Zanon e Freitas (2007) enfatizam a importância do "pensar e discutir" sobre o que é observado. Desse modo, pode-se favorecer a aprendizagem dos estudantes acerca do fenômeno de estudo, assim como oportuniza-se o desenvolvimento de suas habilidades cognitivas (CARVALHO, 2013).

Para a conclusão da atividade experimental, a orientação é de que seja traçada uma explicação significativa sobre o resultado observado, considerando as hipóteses levantadas anteriormente. A intenção é contribuir para que os estudantes construam novos conhecimentos, favorecendo a mudança de crenças e atitudes, bem como as concepções sobre a Ciência (ZANON; FREITAS, 2007). Como culminância dessa etapa, as autoras sugerem a construção de um texto coletivo entre os estudantes. Essa é uma alternativa para que os estudantes exponham e inter-relacionem ou contrastem suas constatações e compreensões com os demais colegas, podendo facilitar ao professor, a identificação dos significados da atividade junto aos estudantes e os aspectos que necessitem ser aprimorados posteriormente.

De modo geral, trata-se de uma proposição que pode orientar o professor no desenvolvimento da experimentação do tipo investigativa, a qual, além dos aspectos procedimentais, abrange fortemente os aspectos cognitivos e atitudinais dos estudantes, contribuindo para a formação integral dos sujeitos (ZANON; FREITAS, 2007; CARVALHO, 2013). Há de se considerar, no entanto, as questões que envolvem a perspectiva do professor frente à prática da experimentação no ensino de Ciências, sendo ele 0 agente responsável por promover e conduzir esse processo no âmbito escolar. Nesse sentido, os direcionamentos do modelo de Zanon e Freitas (2007), têm ampla aplicabilidade às questões abordadas no presente estudo. 


\section{PERCURSO METODOLÓGICO}

A orientação metodológica deste estudo consiste em uma pesquisa de campo com abordagem qualitativa, do tipo exploratória e explicativa tendo como referência os direcionamentos de Marconi e Lakatos (2003) e Gil (2008). Esses autores também fundamentaram a definição e aplicação do instrumento de coleta de dados e demais procedimentos utilizados para a elucidação do problema investigado. Para o processo de análise dos dados, a base teórica utilizada foi a obra de Bardin (2016), direcionada à sistematização analítica por meio de codificações e categorizações teóricas das informações obtidas.

\section{Contexto da pesquisa ${ }^{4}$}

A pesquisa foi desenvolvida no âmbito das escolas municipais e estaduais urbanas da rede pública que dispõem dos anos finais do Ensino Fundamental no município de Uruguaiana/RS. Os sujeitos da pesquisa foram os professores atuantes no ensino de Ciências do $6^{\circ}$ ao $9^{\circ}$ ano nos referidos educandários. Sendo que houve representatividade de professores de todas as escolas que contemplaram o perfil descrito acima e a amostra foi constituída por 63 professores que demonstraram interesse em participar do estudo.

Para a obtenção dos dados, utilizou-se um questionário embasado no modelo proposto por Andrade e Massabini (2011), devidamente adaptado às especificidades desta investigação. Conforme a indicação de Varanda e Benites (2017), após à elaboração do referido instrumento de coleta de dados, 0 mesmo foi submetido à validação quanto à verificação da clareza e coerência das questões que 0 constituíram, considerando os objetivos propostos pelo estudo. Neste processo, o material foi analisado e avaliado por três pesquisadores/doutores atuantes no Ensino Superior de instituições distintas, com formação nas áreas de Ciências Biológicas, Física e Química. Após o retorno das avaliações, realizou-se a triangulação das adequações sugeridas e, conforme a convergência das análises, efetuou-se reformulação do instrumento.

A estrutura final do questionário consistiu em 21 questões agrupadas em duas seções: uma com 10 questões relativas ao perfil dos pesquisados, e a outra com 11 questões sobre 0 contexto geral da experimentação. Dessas últimas, seis estão analisadas no presente estudo, a saber: 1) Na sua opinião, 0 que são atividades experimentais?; 2) Qual sua percepção sobre as práticas experimentais no ensino de Ciências?; 3) Quais seriam os principais objetivos das atividades experimentais?; 4) Você costuma realizar atividades experimentais em suas aulas de Ciências? ( ) Sim, frequentemente, ( ) Sim, às vezes, ( ) Não. Por quê?; 5) Quando você realiza as práticas experimentais, elas costumam ser desenvolvidas antes ou depois da explicação teórica sobre o conteúdo em questão?; 6) 0 que é necessário para que as práticas experimentais sejam mais frequentes no ensino de Ciências?

4 A pesquisa foi desenvolvida após sua aprovação pelo Comitê de Ética e Pesquisa (CEP) da Universidade Federal do Pampa (UNIPAMPA), sob $0 \mathrm{n}^{0} 2.866 .042$ 


\section{Procedimento de análise dos dados}

Com base nos direcionamentos de Bardin (2016), os dados textuais foram submetidos à Análise de Conteúdo (AC). Trata-se de um conjunto de técnicas de análises das comunicações que visa obter indicadores, passíveis ou não de quantificação, que permitam conhecimentos relativos às condições de produção/recepção (variáveis inferidas). Para tanto, utiliza-se de procedimentos sistemáticos e objetivos de descrição do conteúdo das mensagens.

Especificamente, o procedimento de AC consistiu nas três etapas determinadas por Bardin (2016): (1) pré-análise, na qual ocorreu a transcrição e a organização das respostas dos questionários em uma planilha do software Microsoft Excel ${ }^{\circledR}$. Utilizou-se caracteres alfanuméricos para identificação dos sujeitos, a exemplo: P01, onde "P" representa a palavra professor(a) e "01" está relacionado à ordem em que 0 questionário foi armazenado. Posteriormente, realizou-se a leitura flutuante do material a ser analisado; (2) exploração do material, etapa de codificação, na qual definiram-se as palavras-chave ou itens de sentido de cada resposta, para a definição das unidades de registro/ temas. Na sequência, agrupou-se as unidades de registro semelhantes em distintas categorias de análise; (3) tratamento dos resultados, processo em que foram realizadas as inferências pertinentes e a interpretação do conteúdo das respostas.

\section{RESULTADOS E DISCUSSÕES}

Dentre os dados referentes ao perfil dos pesquisados, destaca-se que: $41 \%$ têm formação inicial docente datada de 24 a 44 anos atrás; $65 \%$ não possui formação específica para 0 ensino de Ciências e 40\% deles nunca participaram de cursos de formação continuada.

\section{Categorização dos resultados}

A partir dos resultados da análise de conteúdo, estabeleceu-se as categorias pertinentes quanto à definição conceitual da experimentação; à percepção sobre a realização de experimentos no ensino de Ciências; e aos principais objetivos dessa prática junto aos alunos. Para melhor compreensão, os resultados dessa análise categorial estão expressos conforme cada um dos contextos supracitados. Estruturalmente, apresentam-se as "Categorias Iniciais" bem como as categorias resultantes do reagrupamento progressivo destas, denominadas "Categorias Finais" e o percentual das respostas que compuseram cada categoria.

No Quadro 1 demonstra-se os resultados quanto à definição conceitual da experimentação conforme os professores de Ciências pesquisados. 
Quadro 1 - Categorias sobre a definição conceitual da experimentação

\begin{tabular}{|c|c|c|}
\hline CATEGORIAS INICIAIS & CATEGORIAS FINAIS & \% DE RESPOSTAS \\
\hline Atividades para praticar e comprovar o conhecimento teórico & \multirow{3}{*}{$\begin{array}{l}\text { Atividades de correlação } \\
\text { teoria e prática }\end{array}$} & \multirow{3}{*}{$36,5 \%$} \\
\hline Atividades para demonstração e comprovação da teoria & & \\
\hline Atividades que integram a teoria com a prática & & \\
\hline Atividades com experiências & \multirow{2}{*}{$\begin{array}{c}\text { Realização de } \\
\text { experiências }\end{array}$} & \multirow{2}{*}{$12,7 \%$} \\
\hline Experiências para verificar hipóteses & & \\
\hline Estratégias de ensino para a aprendizagem e desenvolvimento de habilidades & \multirow{3}{*}{$\begin{array}{l}\text { Atividades promotoras da } \\
\text { aprendizagem }\end{array}$} & \multirow{3}{*}{$9,5 \%$} \\
\hline Atividades de ação e interação, que facilitam a aprendizagem & & \\
\hline Atividades para construção do conhecimento e aprendizagem & & \\
\hline Atividades que seguem procedimentos científicos & \multirow{2}{*}{$\begin{array}{l}\text { Atividades de execução } \\
\text { do método científico }\end{array}$} & \multirow{2}{*}{$8,0 \%$} \\
\hline Atividades de observações, testes, registros. & & \\
\hline * & Aulas práticas & $6,3 \%$ \\
\hline * & $\begin{array}{l}\text { Contextualização } \\
\text { do conteúdo }\end{array}$ & $6,3 \%$ \\
\hline \multirow[t]{3}{*}{ * } & $\begin{array}{c}\text { Práticas em laboratório } \\
\text { de Ciências }\end{array}$ & $5,0 \%$ \\
\hline & Diversas $^{5}$ & $12,7 \%$ \\
\hline & Não sabe ou não informou & $3,0 \%$ \\
\hline
\end{tabular}

*0 limitado número e a semelhança das definições não viabilizaram a construção categorias iniciais.

Fonte: Dados da pesquisa

Observa-se no Quadro 01, que a maioria (36,5\%) dos professores definiram conceitualmente a experimentação como atividades de correlação teoria e prática, como constata-se nas seguintes respostas:

P27 - Tudo o que leva 0 aluno a concluir a teoria com a prática;

P44 - Atividades para demonstrar determinadas teorias;

P58 - São atividades práticas que comprovam a teoria estudada.

A correlação evidenciada nos discursos, refere-se à prática, comprovação, demonstração e integração da teoria. Entendimento semelhante foi constado pelo estudo de Guimarães et al. (2018, p. 1169), em que "na maioria das falas dos professores envolvidos, as atividades experimentais aparecem como comprovação da teoria". Trata-se de uma perspectiva reducionista sobre a experimentação, que dificilmente contempla aspectos cognitivos e atitudinais nos estudantes. Fato que pode comprometer o processo de construção do conhecimento científico desses sujeitos (ZANON; FREITAS, 2007).

Como definição conceitual sobre a experimentação, emergiram ainda outras categorias, representadas em menores percentuais de respostas: Realização de experiências (12,7\%); Atividades promotoras da aprendizagem (9,5\%); Atividades de execução do método científico (8,0\%); Aulas práticas (6,3\%); Contextualização do conteúdo (6,3\%); Práticas em laboratório de Ciências (5,0\%). Nesse contexto conceitual, observa-se que poucos professores situam as atividades experimentais no processo de aprendizagem e desenvolvimento do estudante. Conforme Galiazzi e Gonçalves (2004), essa dificuldade dos professores, muitas vezes, é decorrente da falta de fundamentação teórica 
desses profissionais sobre a experimentação com fins didáticos. Trata-se de uma lacuna geralmente oriunda dos processos formativos desses profissionais.

0 Quadro 2 apresenta a categorização quanto à percepção dos professores sobre a experimentação no ensino de Ciências.

Quadro 2 - Categorias sobre as percepções dos professores acerca da experimentação

\begin{tabular}{|c|c|c|}
\hline CATEGORIAS INICIAIS & CATEGORIAS FINAIS & $\%$ DE RESPOSTAS \\
\hline Estímulo ao desenvolvimento integral do estudante & \multirow{2}{*}{$\begin{array}{l}\text { Desenvolvimento e apren- } \\
\text { dizagem dos estudantes }\end{array}$} & \multirow{2}{*}{$21,0 \%$} \\
\hline Importantes para aprendizagem dos estudantes & & \\
\hline Necessária ao ensino de Ciências & \multirow{2}{*}{$\begin{array}{c}\text { Relevância ao } \\
\text { ensino de Ciências }\end{array}$} & \multirow{2}{*}{$19,0 \%$} \\
\hline Importante & & \\
\hline Promovem o interesse dos estudantes pela ciência & \multirow{2}{*}{$\begin{array}{l}\text { Promoção do interesse e } \\
\text { atenção dos estudantes }\end{array}$} & \multirow{2}{*}{$16,0 \%$} \\
\hline Despertam a atenção, favorecendo a construção do conhecimento & & \\
\hline * & $\begin{array}{l}\text { Fixação e assimilação } \\
\text { dos conteúdos }\end{array}$ & $11,0 \%$ \\
\hline Comprovação da teoria & \multirow{2}{*}{ Correlação teoria e prática } & \multirow{2}{*}{$9,5 \%$} \\
\hline Complementação da teoria & & \\
\hline Contato com os procedimentos do método científico & \multirow{2}{*}{$\begin{array}{c}\text { Familiarização com os } \\
\text { procedimentos científicos }\end{array}$} & \multirow{2}{*}{$6,0 \%$} \\
\hline Aproximação do estudante à Ciência & & \\
\hline & Diversas $^{6}$ & $12,5 \%$ \\
\hline & Não sabe ou não informou & $5,0 \%$ \\
\hline
\end{tabular}

*0 limitado número e a semelhança das definições não viabilizaram a construção categorias iniciais.

Fonte: Dados da pesquisa

A partir do Quadro 2, constata-se que há predominância de professores com a percepção de que as atividades experimentais estão associadas ao Desenvolvimento e aprendizagem dos estudantes (21,0\%), têm Relevância ao ensino de Ciências (19,0\%) e atuam na Promoção do interesse e atenção dos estudantes (16,0\%). Como exemplos de respostas temos:

P03 - São atividades que estimulam a criatividade, o trabalho em equipe, a autonomia;

P15 - É uma ferramenta pedagógica com potencial para o ensino.

Esse resultado diferencia-se do panorama acerca das definições conceituais elencadas anteriormente pelos pesquisados. Entende-se, portanto, que mesmo com dificuldades teóricas para a definição de um conceito adequado referente à experimentação, a maioria dos professores percebe a relevância dessa prática para o processo de ensino-aprendizagem em Ciências. Tal compreensão é compartilhada por diversos autores da área, como Giordan (1999), Galiazzi e Gonçalves (2004), Marcondes et al. (2009), Zancul (2011), entre outros.

Entretanto, 0 fato que considerar as atividades experimentais como um artifício para despertar 0 interesse e a atenção dos estudantes, ainda que possa favorecer a aprendizagem dos mesmos, pode também conduzi-los a indevidas interpretações sobre a Ciência (BASSOLI, 2014). Ou seja, priorizar a estética das atividades em detrimento às compreensões sobre as causas do fenômeno observado e às reflexões e discussões acerca dos resultados, pode reduzir os propósitos do conhecimento científico a momentos pontuais e espetaculares. De acordo com Galiazzi e Gonçalves (2004, p. 328) 6 As respostas sem correlação com as demais categorias estabelecidas, foram agrupadas na categoria "Diversas". 
esse entendimento empirista de que "os alunos se motivam justamente por 'verem' algo que é diferente da sua vivência diária, ou seja, pelo 'show' da ciência, é comumente constatado nas falas dos professores de Ciências".

Infere-se que discursos semelhantes foram observados nas respostas de alguns professores deste estudo, sinalizando incompreensões sobre os reais propósitos do ensino de Ciências. A exemplo, tem-se o relato de P61: Trabalhar com o concreto, com o lúdico, despertar mais curiosidade dos alunos.

Na sequência, com menor percentual de respostas, emergiram as categorias Fixação e assimilação dos conteúdos (11,0\%), Correlação teoria e prática (9,5\%) e Familiarização com os procedimentos científicos (6,0\%). Tratam-se de perspectivas que limitam o desenvolvimento das atividades experimentais a reforçar o conteúdo trabalhado, por meio da prática e comprovação da teoria, e muitas vezes, visam apenas o contato dos estudantes com os procedimentos do método científico. Esse contexto, é exemplificado nos seguintes relatos:

P50 - São importantes porque auxiliam na fixação do conteúdo de sala de aula;

P02 - Importante, pois mostra de verdade o que tem na teoria;

P06 - Acho necessária, fundamental, pois leva 0 aluno a passar pelas etapas do método científico.

Segundo Sasseron (2018), percepções dessa natureza estão presentes em muitos contextos educacionais. A autora alerta que tal perspectiva "pode configurar papel importante para o surgimento de aparente aprendizagem, [...] mas não confirmada como internalização de conceitos na tomada de decisões sobre temas correlatos em outros contextos” (SASSERON, 2018, p. 25). Logo, sem muita relevância à construção do conhecimento científico e ao desenvolvimento das principais capacidades dos estudantes, como a criticidade, a reflexão e a autonomia.

A questão de considerar a experimentação como uma forma de mostrar "de verdade" o que consta na teoria e o protagonizar o método científico nas atividades experimentais no ensino de Ciências na Educação Básica, denota que a Ciência ainda está pouco compreendida por alguns professores dessa área. 0 estudo de Marinho, Silva e Guidotti (2018) também identificou ponderações desse tipo junto a professores de Biologia, Física e Química, sendo que a maioria dos discursos apontou que as Ciências Naturais é sustentada pelo método científico. Todo esse contexto, sinaliza e reforça a necessidade de cursos de formação continuada direcionados a contornar tais equívocos, dar suporte conceitual aos professores e assim contribuir para ampliar a qualidade do ensino de Ciências como um todo.

As categorias referentes aos objetivos das atividades experimentais no ensino de Ciências estão apresentadas no Quadro 3.

Quadro 3 - Categorias sobre os objetivos da experimentação no ensino de Ciências

\begin{tabular}{|c|c|c|}
\hline CATEGORIAS INICIAIS & CATEGORIAS FINAIS & $\%$ DE RESPOSTAS \\
\hline Utilizar a prática para comprovar a teoria & \multirow{2}{*}{$\begin{array}{l}\text { Correlacionar e comprovar } \\
\text { a teoria com a prática }\end{array}$} & \multirow{2}{*}{$20,6 \%$} \\
\hline Aplicar a teoria na prática & & \\
\hline Desenvolver a criticidade & \multirow{3}{*}{$\begin{array}{l}\text { Desenvolver as capa- } \\
\text { cidades e envolver os } \\
\text { estudantes }\end{array}$} & \multirow{3}{*}{$16 \%$} \\
\hline Despertar a curiosidade & & \\
\hline Promover o interesse pela ciência & & \\
\hline Possibilitar novas oportunidades de aprender & \multirow{2}{*}{$\begin{array}{l}\text { Facilitar o processo de } \\
\text { aprendizagem }\end{array}$} & \multirow{2}{*}{$14,3 \%$} \\
\hline Promover a construção do conhecimento & & \\
\hline
\end{tabular}




\begin{tabular}{|c|c|c|}
\hline Correlacionar a ciência e o cotidiano dos estudantes & \multirow{2}{*}{$\begin{array}{c}\text { Contextualizar o } \\
\text { ensino de Ciências }\end{array}$} & \multirow{2}{*}{$14,3 \%$} \\
\hline Promover o conhecimento sobre a aplicabilidade da ciência no cotidiano & & \\
\hline Sedimentar conteúdos teóricos & \multirow{2}{*}{$\begin{array}{l}\text { Facilitar a assimilação } \\
\text { do conteúdo }\end{array}$} & \multirow{2}{*}{$9,5 \%$} \\
\hline Fixar os conteúdos trabalhados & & \\
\hline Propiciar a vivência do método científico & \multirow{2}{*}{$\begin{array}{c}\text { Familiarizar o } \\
\text { estudante com os } \\
\text { métodos científicos }\end{array}$} & \multirow[b]{2}{*}{$6,3 \%$} \\
\hline Exercitar a observação visando a conclusão sobre o tema. & & \\
\hline & Diversas $^{7}$ & $11 \%$ \\
\hline & Não sabe ou não informou & $8 \%$ \\
\hline
\end{tabular}

*0 limitado número e a semelhança das definições não viabilizaram a construção categorias iniciais

Fonte: Dados da pesquisa

Conforme os dados do Quadro 3, percebe-se que para a maioria dos professores, os objetivos das atividades experimentais no ensino de Ciências referem-se a "Correlacionar e comprovar a teoria com a prática" (20,6\%). Para exemplificar essa categoria, elencamos duas respostas:

P25 - Provar cientificamente que os conceitos são verdadeiros;

P30 - Colocar em práticas os conteúdos, ou seja, conceitos aprendidos, poder constatar esses conceitos na prática.

Assim como acerca da definição conceitual sobre a experimentação, evidencia-se novamente a correlação teoria e prática, principalmente com um viés em que se utiliza a prática para verificar a teoria. Resultados semelhantes foram constatados no estudo de Guimarães et al. (2018, p. 1169), os autores descrevem que "na maioria das falas dos professores envolvidos, as atividades experimentais aparecem como comprovação da teoria". Conforme Castelan e Rinaldi (2018, p. 314), "as atividades experimentais tendem a ser consideradas por muitos professores como mera atividade de manipulação para comprovação da teoria, em detrimento à interação e à reflexão sobre os conceitos".

Como uma alternativa a minimizar essa problemática, Zanon e Freitas (2007) propõem que durante a prática de experimentos, os professores precisam envolver a reflexão e instigar os estudantes, orientando-os a posicionarem-se ativamente frente a realidade apresentada. Na mesma perspectiva, Uhmann e Alves (2019, p. 116) destacam que "a experimentação permite aos sujeitos escolares mais condição de reflexão crítica, estimulando 0 aprendizado por meio do questionamento reconstrutivo em grupo de forma colaborativa".

Contudo, salienta-se que alguns professores elencaram que o objetivo das atividades experimentais pautam-se em "Desenvolver as capacidades e envolver os estudantes" (16,0\%); "Facilitar 0 processo de aprendizagem" (14,3\%); e "Contextualizar o ensino de Ciências" (14,3\%). Como exemplo, tem-se as seguintes respostas:

P45 - Desenvolver no educando o espírito crítico e de novas formas de descoberta;

P01 - Contribuir para a aprendizagem dos conteúdos necessários para a vida e para o desenvolvimento das habilidades dos alunos;

P18 - Momento para questionamento dos alunos e correlacionar o conteúdo com a realidade.

A atribuição de objetivos importantes à experimentação, nos permite inferir que, de modo geral, esses professores enfatizam aspectos que podem contribuir significativamente para a formação cidadã dos estudantes. Trata-se de uma perspectiva promissora para o desenvolvimento das atividades experimentais no ensino de Ciências. Nesse sentido, Suart (2008) e Carvalho (2013) enaltecem a

7 As respostas sem correlação com as demais categorias estabelecidas, foram agrupadas na categoria "Diversas". 
relevância da experimentação como um recurso pedagógico que contempla o desenvolvimento de diversas habilidades dos estudantes, principalmente as de caráter cognitivo e de tomada de decisões.

Ainda que com um menor quantitativo de respostas, as categorias "Facilitar a assimilação do conteúdo" (9,5\%) e "Familiarizar o estudante com os métodos científicos" (6,3\%), também representam as respostas dos professores acerca dos objetivos da experimentação no ensino de Ciências. A exemplo de respostas presentes nessas categorias tem-se:

P50 - Fixação do conteúdo teórico desenvolvido em sala de aula.

P11 - Demonstrar como é realizado um experimento científico e proporcionar a vivência e a manipulação dos materiais para os alunos.

Outra vez, evidencia-se uma perspectiva pouco significativa da experimentação como meio de abordagem do conhecimento científico e desenvolvimento dos alunos. De acordo com Zanon e Uhmann (2012), trata-se de um caráter superficial que muitas atividades experimentais apresentam, uma vez que há limitação restrita a um determinado ponto de interesse, nesse caso, ao conteúdo e ao método científico.

\section{A prática da experimentação}

Referente à realização de atividades experimentais, dos 63 professores pesquisados, 25\% informaram que realizam frequentemente, $52 \%$ responderam que realizam às vezes e $23 \%$ relataram que não desenvolvem tais atividades. Resultados similares foram evidenciados no estudo de Castelan e Rinaldi (2018), no qual a maioria dos professores mencionaram que a experimentação não é uma prática regular em suas aulas. Contudo, tanto na pesquisa dos referidos autores e em outras, quanto nos resultados do presente estudo, ainda que as atividades experimentais não sejam frequentes, a maioria dos professores reconhece a relevância dessas práticas ao ensino de Ciências. Esse é um paradoxo comumente presenciado no âmbito das escolas públicas brasileiras (ANDRADE; COSTA, 2016).

Sobre os motivos para não realizar a experimentação, os principais foram: a falta de materiais e laboratório de Ciências; a indisciplina dos alunos e o despreparo formativo, conforme evidencia-se nesses dois discursos:

P55 - Não realizo, porque não tem como fazer, pois faltam materiais didáticos, falta verba e tem ainda a indisciplina dos alunos.

P41 - Não realizo, porque não existe Laboratório de Ciências na escola, e em nossa formação nesta área não havia preparo para aulas práticas.

Conforme a literatura da área, de modo geral, esses fatores são elencados como as principais impossibilidades à prática da experimentação no ensino de Ciências (SILVA; ZANON, 2000; PEREIRA; FUSINATO, 2015; CASTELAN; RINALDI, 2018; GUIMARÃES et al., 2018). Isso denota um possível despreparo conceitual, atitudinal, pedagógico e até mesmo emocional dos professores, dificultando a inserção das atividades experimentais em suas aulas. Além de expor as frequentes dificuldades inerentes ao contexto da maioria das escolas públicas (ANDRADE; COSTA, 2016).

\section{Momento e procedimentos da prática experimental}

Questionados quanto ao momento em que realizam as atividades experimentais com os estudantes, $44 \%$ dos professores indicaram que desenvolvem tais atividades depois da abordagem teórica. Como justificativa, tem-se como exemplo os seguintes discursos: 
P19 - Sempre depois, pois penso que é o momento que eles efetivam conhecimento.

P36 - Depois, pois acredito que seja necessário um embasamento teórico antes. A prática precisa ser contextualizada ao que está sendo estudado.

Em menores proporções, os demais professores informaram que as práticas experimentais costumam ser realizadas antes ou depois da teoria (13\%), depende do conteúdo (11\%) ou antes da teoria (9\%), o restante não realiza a experimentação.

Sobre a maioria dos pesquisados desenvolver as atividades experimentais depois da explanação teórica do conteúdo, percebe-se a tendência comprobatória com que os experimentos são desenvolvidos. Contexto já constatado anteriormente entre os professores, no tocante às definições conceituais e aos objetivos atribuídos a tais atividades. Conforme Oliveira (2010, p. 144) "a atividade experimental também pode [...] ser um espaço para construção de novos conhecimentos e, por esse motivo, nem sempre deve estar "presa" à abordagem expositiva prévia do conteúdo".

Por meio deste estudo, também constatou-se quais os principais procedimentos utilizados pelos professores para a realização das atividades experimentais junto aos estudantes. Em síntese, os experimentos demonstrativos, aqueles realizados pelo professor, a construção de modelos didáticos, a pesquisa de campo e a construção de horta e jardim foram elencados como as principais práticas experimentais desenvolvidas entre os pesquisados. As respostas convergiram ainda sobre os trabaIhos em grupos utilizando materiais de baixo custo providenciados pelos estudantes, seguindo um roteiro para observações e registros e como finalização, apresentações de seminários ou elaboração de um relatório sobre a prática.

Presume-se que, possivelmente, a preferência por experimentos demonstrativos representa a melhor alternativa de experimentação àqueles professores que trabalham com turmas numerosas e/ ou com problemas indisciplinares. Considerando que essa foi uma problemática evidenciada nas respostas dos pesquisados. Tal prática, ainda que defendida por alguns autores (GASPAR; MONTEIR0, 2005; KRASILCHIK, 2008), pela praticidade de desenvolvimento, também é criticada por monopolizar as ações ao professor (CARVALHO, 2013). Assim, para dar significância à experimentação demonstrativa, Oliveira (2010) sugere que antes, durante e depois da prática, o professor lance questionamentos aos estudantes, de modo a mantê-los centrados em todas as etapas. Isso torna a prática demonstrativa pedagogicamente válida.

Sobre os demais contextos mencionados como práticas experimentais, infere-se que há alguns equívocos. Por exemplo, ao considerar a pesquisa de campo como atividade experimental, talvez os professores percebam 0 ensino por investigação como atividades práticas investigativas, 0 que não são (BASSOLI, 2014). Conforme a autora, o primeiro caso (ensino por investigação) não se baseia necessariamente na experimentação, já o segundo sim, no caso, as atividades práticas investigativas. Isso denota a fragilidade conceitual e teórica dos professores pesquisados, acerca das particularidades inerentes às atividades experimentais no ensino de Ciências.

\section{Principais necessidades}

Ainda que alguns participantes (14\%) entendam que é necessária apenas a disposição do professor, a maioria (86\%) das respostas centram-se nas demandas por Materiais e Recursos, Laboratório de Ciências, Investimento financeiro, Turmas menores, Tempo para planejamento e desenvolvimento das atividades, Recursos humanos para auxiliar e Formação e preparo para os professores. Algumas dessas demandas estão representadas nas respostas de P06, P54 e P55: 
P06 - [...] que o professor tenha mais tempo para preparar tais atividades, pois muitas vezes nossa rotina cheia de períodos não nos deixa espaço para tal.

P54 - Necessidade de um Laboratório de Ciências com materiais adequados que nos auxiliassem a desenvolver as práticas.

P55 - Cursos preparatórios para os professores, com relatos de experiências e trabalhos vivenciados.

Destaca-se que essas reivindicações são legítimas e explicitam parte do cenário de precarização das condições de trabalho nas escolas públicas: carga horária elevada, falta de suporte estrutural e material e lacunas formativas. Assim, tal situação pode ter correlação direta com a desmotivação dos professores em inovar a prática educativa com atividades experimentais, favorecendo cada vez mais a priorização de aulas estritamente teóricas (SANTOS; SOUZA, 2016).

\section{CONSIDERAÇÕES FINAIS}

No presente trabalho, investigou-se o contexto da experimentação junto aos professores de Ciências $6^{\circ}$ ao $9^{\circ}$ ano das escolas públicas urbanas de Uruguaiana/RS. A pesquisa contemplou as compreensões desses professores sobre o tema, o modo como desenvolvem as práticas e as principais demandas para que tais práticas sejam mais frequentes. Como principais resultados, evidenciou-se que tanto a definição conceitual, quanto os objetivos atribuídos à experimentação pela maioria dos pesquisados, refere-se à correlação entre a teoria e a prática, em que a teoria é comprovada ou demonstrada por meio da prática. Contudo, predominantemente, os professores percebem a relevância da experimentação para a aprendizagem e desenvolvimento das capacidades dos estudantes.

Constatou-se também que as atividades experimentais não são frequentes entre os participantes. Quando realizadas, geralmente as práticas são de forma demonstrativa, depois da explanação teórica, em grupos, seguindo um roteiro e finalizada por meio de apresentações ou elaboração de relatórios. As demandas por recursos materiais, estruturais, financeiros e formativos estão entre as principais necessidades elencadas no que tange a efetivação da experimentação no ensino de Ciências no contexto pesquisado.

A partir dos resultados obtidos, infere-se que há determinadas distorções em relação à essência da experimentação e seus propósitos didático-pedagógicos na promoção do conhecimento científico e desenvolvimento dos estudantes. A perspectiva de utilizar a experimentação com o mero intuito de comprovar a teoria trabalhada em sala de aula, denota a falta de aprofundamento teórico sobre essa vertente metodológica e suas potencialidades ao processo de ensino-aprendizagem em Ciências. Assim, considerando o tempo e a área de formação da maioria dos pesquisados, bem como a irrisória participação destes em cursos de formação continuada, entende-se que além do suporte material e estrutural, é necessária a atualização teórico-pedagógica desses profissionais. Para tanto, os professores devem ser e/ou estar motivados a buscar por tal capacitação, o que na maioria das vezes infelizmente não ocorre.

Diante do exposto, presume-se que as constatações apresentadas por este estudo, além de ter relevância às equipes diretivas das escolas participantes e suas mantenedoras, traz importantes contribuições à área do ensino de Ciências. Isso porque apresenta-se um panorama geral sobre os principais fatores que permeiam a prática de atividades experimentais no componente de Ciências. São constatações que possivelmente também fazem parte de outros contextos educativos, portanto, infere-se que podem servir como ponto de partida a outras pesquisas sobre o tema. 
Por fim, considera-se ainda que "investigar as concepções dos professores sobre a finalidade da experimentação em sala de aula pode auxiliar na reflexão sobre as práticas de ensino e [...] na compreensão sobre a visão de ciência que eles manifestam" (SOUZA; RODRIGUES; RAMOS, 2016, p. 587). Desse modo, pode-se evidenciar as principais lacunas presentes na prática educativa desses profissionais para, sobretudo, suscitar reflexões, discussões e alternativas que venham contribuir à qualidade do ensino de Ciências. Nesse sentido, uma importante alternativa, seria a disponibilização de materiais com atividades experimentais de baixo custo aos professores, bem como uma oferta regular, mensal ou bimestral, de minicursos ou oficinas sobre a experimentação no ensino de Ciências. $\mathrm{E}$, dessa forma, dar suporte aos professores para que as atividades experimentais possam ser mais frequentes e desenvolvidas adequadamente.

\section{REFERÊNCIAS}

ANDRADE, T. Y. I.; COSTA, M. B. 0 Laboratório de Ciências e a Realidade dos Docentes das Escolas Estaduais de São Carlos-SP. Química Nova na Escola, v. 38, n. 3, p. 208-214, 2016. Disponível em: https://bit.ly/3E3Fgip. Acesso em: 08 out. 2021.

ANDRADE, M. L. F. de; MASSABINI. V. G. 0 desenvolvimento de atividades práticas na escola: um desafio para os professores de ciências. Ciência \& Educação, v. 17, n. 4, p. 835-854, 2011. Disponível em: https://bit.ly/3aXAKFI. Acesso em: 08 out. 2021.

BARDIN, L. Análise de conteúdo. Lisboa: Edições 70, 2016.

BASSOLI, F. Atividades práticas e 0 ensino-aprendizagem de ciência(s): mitos, tendências e distorções. Ciência \& Educação, v. 20, n. 3, p. 579-593, 2014. Disponível em: https://bit.ly/3AYRabs. Acesso em: 08 out. 2021.

BORGES, A. T. Novos rumos para o laboratório escolar de Ciências. Caderno Brasileiro de Ensino de Física, v. 19, n. 3, p. 291-313, 2002. Disponível em: https://bit.ly/3b0iJGs. Acesso em: 08 out. 2021.

BRASIL. Ministério da Educação. Secretaria de Educação Básica. Diretrizes Curriculares Nacionais Gerais da Educação Básica. Diretoria de Currículos e Educação Integral. Brasília: MEC, SEB, DICEI, 2013. Disponível em: https://bit.ly/3aViQ6l. Acesso em: 12 out. 2021.

BRASIL. Ministério da Educação. Base Nacional Curricular Comum, 2017. Disponível em: https://bit.ly/3DTRZUw. Acesso em: 12 out. 2021.

CARVALHO, A. M. P. 0 ensino de Ciências e a proposição de sequências de ensino investigativas. In: CARVALHO, A. M. P. (Org.) Ensino de Ciências por investigação: Condições para implementação em sala de aula. São Paulo: Cengage Learning, 2013. p. 1-19.

CASTELAN, S. S.; RINALDI, C. A atividade experimental no ensino de Ciências Naturais: contribuições e contrapontos. Experiências no Ensino de Ciências, v. 13, n. 1, p. 306-320, 2018. Disponível em: https://bit.ly/30LQz0j. Acesso em: 08 out. 2021.

CERRI, Y. L. N. S; TOMAZELLO, M. G. C. Crianças aprende melhor Ciências por meio da experimentação? In: PAVÃO, A. C.; FREITAS, D. de. (Org.). Quanta Ciência há no Ensino de Ciências. São Carlos: EdUFSCar, 2011. p. 71-79. 
GALIAZZI, M. C.; GONÇALVES, F. P. A natureza pedagógica da experimentação: uma pesquisa na licenciatura em Química. Química Nova. v. 27, n. 20, p. 326-331, 2004. Disponível em: https://bit.ly/3DVSEFd. Acesso em: 08 out. 2021.

GASPAR, A; MONTEIRO, I, C. Atividades experimentais de demonstrações em sala de aula: Uma análise segundo 0 referencial da teoria de Vygotsky. Investigações em Ensino de Ciências. v. 10, n. 2, p. 227-254, 2005. Disponível em: https://bit.ly/3E2J6bg. Acesso em: 08 out. 2021.

GIANI, K. A experimentação no Ensino de Ciências: possibilidades e limites na busca de uma Aprendizagem Significativa. Dissertação de Mestrado. Brasília: Universidade de Brasília, 2010. Disponível em: https://bit.ly/2XvxqON. Acesso em: 08 out. 2021.

GIL, A. C. Métodos e técnicas de pesquisa social. 6. ed. São Paulo: Atlas, 2008.

GIORDAN, M. 0 papel da experimentação no ensino de Ciências. Química Nova na Escola. v. 10, n. 10, p. 43-49, 1999. Disponível em: https://bit.ly/3G4PINN. Acesso em: 08 out. 2021.

GUIMARÃES, L. et al. Ensino de Ciências e experimentação: reconhecendo obstáculos e possibilidades das atividades investigativas em uma formação continuada. Revista Thema. v. 15, n. 3, p. 1164-1174, 2018. Disponível em: https://bit.ly/ 3BZLfnP. Acesso em: 08 out. 2021.

KRASILCHIK, M. 0 professor e o currículo das ciências. São Paulo: Edusp, 1987.

KRASILCHIK, M. Prática de ensino de biologia. 4. ed., São Paulo: Editora Edusp, 2008.

MARINHO, J. C. B.; DA SILVA, F. F.; GUIDOTTI, C. dos S. Concepções de Ciência e Conhecimento de professores participantes de um curso de especialização em educação em ciências. VIDYA, v. 38, n. 2, p. 53-69, 2018. Disponível em: https://bit.ly/3C4vbRB. Acesso em: 08 out. 2021.

LANGHI, R. Projeto Eratóstenes Brasil: autonomia docente em atividades experimentais de Astronomia. Caderno Brasileiro de Ensino de Física, v. 34, n. 1, p. 6-46, 2017. Disponível em: https://bit.ly/30K13gG. Acesso em: 08 out. 2021.

MARCONI, M. de A; LAKATOS, E. M. Fundamentos de metodologia científica. 5. ed. São Paulo: Atlas, 2003.

MARCONDES, M. E. R. et al. Materiais instrucionais numa perspectiva CTSA: uma análise de unidades didáticas produzidas por professores de química em formação continuada. Investigações em Ensino de Ciências, v. 14, n. 2, p. 281-298, 2009. Disponível em: https://bit.ly/2ZbQaUc. Acesso em: 08 out. 2021.

MOREIRA, M. C. do A.; PINHÃO, F. Representações discursivas sobre experimentação didática de Mestrandos em ensino de ciências. Ensaio: Pesquisa em Educação em Ciências, p. 1-22, 2018. Disponível em: https://bit.ly/3jk0u3z. Acesso em: 08 out. 2021.

MORTIMER, E. F.; SCOTT, P. Atividades discursivas nas salas de aulas de ciências: uma ferramenta sócio-cultural para analisar e planejar o ensino. Investigações no Ensino de Ciências, v. 7, n. 3, p. 283-306, 2003. Disponível em: https:// bit.ly/3jfZA8f. Acesso em: 08 out. 2021. 
PEREIRA, V. M.; FUSINATO, P. A. Possibilidades e dificuldades de se pensar aulas com atividades experimentais: o que pensam os professores de Física. Experiências em Ensino de Ciências, v. 10, n. 3, p. 120-143, 2015. Disponível em: https://bit.ly/2Zhl6T4. Acesso em: 08 out. 2021.

OLIVEIRA, J. R. S. de. Contribuições e abordagens das atividades experimentais no ensino de ciências: reunindo elementos para a prática docente. Acta Scientiae, v. 12, n. 1, jan. /jun. 2010. Disponível em: https://bit.ly/3jmS8Z3. Acesso em: 08 out. 2021.

RIO GRANDE DO SUL. Secretaria de Estado da Educação, Departamento Pedagógico, R 585r União Nacional dos Dirigentes Municipais de Educação. Referencial Curricular Gaúcho: Ciências da Natureza. v. 1, Porto Alegre, 2018. Disponível em: https://bit.ly/3BVS5KS. Acesso em: 12 out. 2021.

ROSITO, B. A. 0 ensino de Ciências e a experimentação. In: R. Moraes (Ed.), Construtivismo e ensino de Ciências: concepções epistemológicas e metodológicas 3. ed., Porto Alegre: EDIPUCRS, 2008. p. 195-208.

SANTOS G. G.; SOUZA, D. N. Experimentação real versus experimentação ideal no ensino de ciências e a prática do pensamento crítico. Scientia Plena, v. 12, n. 11, p. 1-11, 2016. Disponível em: https://bit.ly/3E2zeP8. Acesso em: 08 out. 2021.

SASSERON, L. H. Práticas em aulas de Ciências: 0 estabelecimento de interações discursivas no ensino por investigação. Tese. 187f. (Livre Docência) - Faculdade de Educação da Universidade de São Paulo, São Paulo, 2018. Disponível em: https://bit.ly/3jgE0Ao. Acesso em: 08 out. 2021.

SASSERON, L. H. Interações discursivas e investigação em sala de aula: o papel do professor. In: Anna Maria Pessoa de Carvalho. (Org.). Ensino de Ciências por investigação: condições para implementação em sala de aula. 1. ed. São Paulo: Cengage Learning, v. 1, 2013. p. 41-62.

SILVA, D. P. ; MARCONDES, M. E. R. Questões propostas no planejamento de atividades experimentais de natureza investigativa no ensino de química: reflexões de um grupo de professores. Enseñanza de las ciencias: revista de investigación y experiencias didácticas, n. Extra, p. 2857-2862, 2017. Disponível em: https://bit.ly/3jj2134. Acesso em: 08 out. 2021.

SILVA, L. D. A. e ZANON, L. B. A experimentação no ensino de Ciências. In: SCHNETZLER, R. P. ; ARAGÃO, R. M. R. de (Org.). Ensino de ciências: fundamentos e abordagens. São Paulo: CAPES/UNIMEP, 2000. p. 120-153.

SOUZA, V. M. de; RODRIGUES, S. S.; RAMOS, M. G. A experimentação em sala de aula: concepções de professores de Ciências e Matemática. Indagatio Didactica, v. 8, n. 1, p. 584-598, 2016. Disponível em: https://bit.ly/3nfETu2. Acesso em: 08 out. 2021.

SUART, R. de C. Habilidades cognitivas manifestadas por alunos do ensino médio de química em atividades experimentais investigativas. $218 \mathrm{f}$. Dissertação (Mestrado em Ensino de Ciências) - Universidade de São Paulo, São Paulo, 2008. Disponível em: https://bit.ly/3IXcZ6M. Acesso em: 09 out. 2021.

UHMANN, R. I. M.; ALVES, R. C. 0 potencial da experimentação nos livros de Ciências do $8^{0}$ ano. VIDYA, v. 39, n. 1 , p. 115-129, 2019. Disponível em: https://bit.ly/3C21e4z. Acesso em: 08 out. 2021. 
VARANDA, S. S.; BENITES, L. C. Validação de instrumentos na pesquisa qualitativa: contribuições de um professor pesquisador em formação. In: XIII CONGRESSO NACIONAL DE EDUCAÇÃO, 2017, Curitiba. Anais... Curitiba: PUCPR, p. 23841-23850. 2017. Disponível em: https://bit.ly/3pmhxpE. Acesso em: 08 out. 2021.

ZANCUL, M. C. de S. 0 ensino de Ciências e a experimentação: algumas reflexões. In: PAVÃO, A. C.; FREITAS, D. de. (Org.). Quanta Ciência há no Ensino de Ciências. São Carlos: EdUFSCar, 2011. p. 63-68.

ZANON, D. A. V. ; FREITAS, D. de. A aula de ciências nas séries iniciais do ensino fundamental: ações que favorecem a sua aprendizagem. Ciências \& Cognição, v. 10, p. 93-103, 2007. Disponível em: https://bit.ly/2ZhmdSK. Acesso em: 08 out. 2021.

ZANON, L. B.; UHMANN, R. I. M. 0 desafio de inserir a Experimentação no Ensino de Ciências e entender a sua função Pedagógica. In: XVI Encontro Nacional de Ensino de Química (XVI ENEQ), 2012, Salvador. Anais... Disponível em: https://bit.ly/3pmhzhg. Acesso em: 08 out. 2021.

RECEBIDO EM: 27 abr. 2021

CONCLUÍDO EM: 12 out. 2021 